\title{
PENGARUH KONSELING KELOMPOK PENDEKATAN ANALISIS TRANSAKSIONAL TEKNIK ROLE PLAYING TERHADAP PENURUNAN BULLYING
}

\author{
Rizqi Puri Handayani ${ }^{1}$, Harwanti Noviandari ${ }^{2}$ \\ Fakultas Keguruan dan Ilmu Pendidikan, Universitas PGRI Banyuwangi \\ Email : chachamahacaracy@yahoo.com ${ }^{1}$ \\ Email : hnoviandari83@gmail.com²
}

\begin{abstract}
Abstrak
Perilaku bullying merupakan kekerasan yang potensial terjadi di sekolah. Terjadinya perilaku bullying dari ejekan dan cemoohan yang sederhana seperti itulah akan terakumulasi menjadi konflik fisik. Bullying memberikan dampak negatif pada korban bullying dan dapat memunculkan perilaku yang tidak diinginkan. Tujuan penelitian ini adalah untuk menguji pengaruh konseling kelompok pendekatan analisis transaksional dengan teknik role playing terhadap penurunan perilaku bullying pada siswa SMA Negeri Darussholah Singojuruh. Metode yang digunakan dalam penelitian ini adalah desain eksperimen dengan menggunakan rancangan control group Pretest and Posttest design. Sampel penelitian sebanyak 15 orang siswa yang memiliki perilaku bullying. Teknik pengambilan sampel menggunakan sampel purposive. Dalam penelitian ini analisis data menggunakan analisis data statistik (kuantitatif).
\end{abstract}

Kata Kunci : Teknik Role Playing, Perilaku Bullying.

\begin{abstract}
Bullying behavior is a potential violence in schools. The occurrence of bullying behavior from such ridiculous and derisive mockery will accumulate into physical conflict. Bullying has a negative impact on victims of bullying and can lead to undesirable behavior. The purpose of this study was to examine the effect of group counseling of transactional analysis approach with role playing technique to decrease bullying behavior on students of SMA Negeri Darussholah Singojuruh. The method used in this research is experimental design using control group design Pretest and Posttest design. The sample of the study were 15 students who had bullying behavior. Sampling technique using purposive sample. In this study data analysis using statistical data analysis (quantitative).
\end{abstract}

Keywords : Role Playing Techniques, Bullying Behavior.

\section{PENDAHULUAN}

Sekolah memiliki peranan penting untuk mempersiapkan siswa meraih kesuksesan di masa depan, yaitu dengan mengembangkan potensi baik yang berhubungan dengan mata pelajaran maupun yang berhubungan dengan pengembangan diri pribadi, sosial, dan karier dalam kehidupannya. Sekolah merupakan faktor penentu bagi perkembangan kepribadian siswa baik dalam cara berpikir, bersikap, maupun cara berperilaku. Di sekolah siswa diajarkan berpikir, bersikap, maupun berperilaku secara baik. 
ISBN: 978-602-72362-7-1

Siswa menjadi faktor penentu, sehingga dapat mempengaruhi segala sesuatu yang diperlukan untuk mencapai tujuan belajarnya.

Menurut pasal 1 ayat 4 Undang-undang (UU) RI No. 20 tahun 2013. Mengenai sistem pendidikan nasional, dimana siswa adalah anggota masyarakat yang berusaha mengembangkan diri mereka melalui proses pendidikan pada jalur dan jenjang dan jenis pendidikan tertentu.

Pada umumnya siswa biasanya tidak dapat mengontrol dirinya. Sehingga dengan ketidakstabilan emosinya tersebut dapat mempengaruhi kepribadiannya itu. Pada saat menghadapi suatu problematika mereka tidak bisa mengatasinya. Problematika yang sering dialami oleh siswa seperti; penyesuaian diri rendah, tawuran antar siswa dan salah satunya ialah kekerasan yang terjadi pada siswa yang dikenal dengan istilah bullying.

Bullying merupakan kekerasan yang potensi terjadi di sekolah. Menurut Sejiwa foundation bullying, diartikan, sebagai tindakan penggunaan kekuasaan atau kekuatan untuk menyakiti seseorang atau sekelompok orang sehingga korban merasa tertekan, trauma dan tak berdaya. Bullying merupakan satu aksi atau serangkaian aksi negatif yang seringkali agresif dan manipulatif, dilakukan oleh satu orang lebih terhadap orang lain atau beberapa orang selama kurun waktu tertentu, bermuatan kekerasan, dan melibatkan ketidak seimbangan kekuatan. Bullying biasaya terjadi dari peristiwa ejekan dan cemoohan yang sederhana seperti itulah kelak akan terakumulasi menjadi konflik fisik atau setidaknya akan sangat mengguncang psikis anak.

Di Indonesia sendiri, kasus bullying di sekolah sudah merajalela. Baik di tingkat sekolah dasar, menengah, sampai perguruan tinggi. Dari 2011 hingga Agustus 2014, KPAI mencatat 369 pengaduan terkait masalah tersebut. Jumlah itu sekitar $25 \%$ dari total pengaduan di bidang pendidikan sebanyak 1.480 kasus. Keadaan ini tentunya tidak dapat dibiarkan terus menerus. Dilihat dari permasalahan yang terjadi di sekolah dapat digunakannya konseling kelompok pendekatan analisis transaksional (AT) dengan teknik role playing sebagai suatu penanganan terhadap penurunan perilaku bullying.

Konseling kelompok diberikan agar siswa merasakan dirinya menjadi bagian dalam kelompok sehingga diperlukan kerjasama dalam menyelesaikan sesuatu. Layanan konseling kelompok mengaktifkan dinamika kelompok untuk membahas berbagai hal yang berguna bagi pengembangan pribadi dan pemecahan masalah individu (siswa) yang menjadi peserta layanan.

Pendekatan Analisis Transaksional (AT) merupakan pendekatan yang dapat digunakan pada setting individual maupun kelompok. AT menekankan aspek-aspek kognitif-rasional-behavioral dan berorientasi kepada peningkatan kesadaran 


\section{FKIP Universitas PGRI Banyuwangi Seminar Nasional}

Pendidikan Budaya dan Sejarah: "Dibalik Revitalisasi Budaya"

ISBN: 978-602-72362-7-1

sehingga klien akan mampu membuat keputusan-keputusan baru dan mengubah cara hidupnya.

Role playing merupakan sebuah model pengajaran yang berasal dari dimensi pendidikan individu maupun sosial. Model ini membantu masing-masing siswa untuk menemukan makna pribadi dalam dunia sosial mereka dan membantu memecahkan dilema pribadi dalam bantuan kelompok. Dimensi sosial model ini memudahkan individu untuk bekerja sama dalam menganalisis kondisi sosial, khususnya masalah kemanusiaan (Miftahul Huda, 2013).

\section{KAJIAN LITERATUR DAN PENGEMBANGAN HIPOTESIS}

Menurut Natawidjaja (dalam Afriana dkk, 2014) mengartikan konseling sebagai usaha bantuan untuk mencapai pengertian tentang dirinya sendiri dalam interaksinya dengan masalah-masalah yang dihadapinya saat ini dan saat yang akan datang. Kelompok pada dasarnya didukung dan dibentuk melalui berkumpulnya sejumlah orang. Adanya suatu kelompok tidak harus diawali dengan adanya kerumunan.

Konseling kelompok dapat bertujuan sebagai remedi, pengembangan, atau pencegahan. Kelompok pada dasarnya didukung dan dibentuk melalui berkumpulnya sejumlah orang. konseling kelompok adalah suatu bantuan yang diberikan oleh konselor kepada klien dalam memecahkan masalah yang dihadapinya melalui dinamika kelompok dan dapat bertukar pikiran dengan anggota kelompok lain.

Tahapan dalam layanan konseling kelompok ada empat (dalam Hermansyah, 2017), yakni (a)Tahapan pembentukan, Tahapan pembentukan merupakan tahap pengenalan dan tahapan perlibatan awal dalam kelompok. Tahapan ini sangat perlu sebagai dasar pembentukan dinamika kelompok; (b)Tahap peralihan, Pada tahapan ini pemimpin kelompok perlu kembali mengalihkan perhatian anggota kelompok tentang kegiatan apa yang akan dilakukan selanjutnya, menjelaskan jenis kelompok (kelompok tugas dan kelompok bebas), menawarkan atau mengamati aapakah para anggota sudah siap menjalani kegiatan pada tahap selanjutnya, membahas suasana yang terjadi dan meningkatkan kemampuan keikutsertaan anggota; (c)Tahap kegiatan, Tahap kegiatan merupakan tahap inti dari layanan konseling kelompok, dalam tahap ini hubungan antar anggota kelompok tumbuh dengan baik; (d)Tahap pengakhiran, Pada tahapan ini pemimpin kelompok mengemukakan bahwa kegiatan akan segera diakhiri, meminta kepada para anggota kelompok untuk mengemukakan perasaan tentang kegiatan yang telah dijalani, serta membahas kegiatan lanjutan. 
Pendekatan analisis transaksional ini dikembangkan oleh Eric Berne, (dalam Corey, 2010) berlandasan suatu teori kepribadian yang berkenaan dengan analisis struktural dan transaksional. Teori ini menyajikan suatu kerangka bagi analisis terhadap tiga kedudukan ego yang terpisah, yaitu; orang tua, orang dewasa, dan anak. Menurut Corey analisis transaksional menekankan pada aspek kognitif, rasional dan tingkah laku dari kepribadian.

Tujuan dasar Analisis Transaksional (dalam Corey, 2010) adalah membantu klien dalam membuat putusan-putusan baru yang menyangkut tingkah lakunya sekarang dan arah hidupnya. Inti terapi ini adalah menggantikan gaya hidup yang ditandai oleh permainan yang manipulative dan oleh skenario-skenario hidup yang mengalahkan diri, dengan gaya hidup otonom yang ditandai oleh kesadaran, spontanitas, dan keakraban.

Permainan Peran (role playing) biasanya digunakan dalam konseling kelompok dimana melibatkan orang lain. Anggota kelompok lain dapat berperan sebagai ego state yang bermasalah dengan konseli. Melalui kegiatan ini konseli berlatih dengan anggota kelompok untuk bertingkah laku sesuai dengan apa yang akan diuji coba di dunia nyata. Model ini membantu masingmasing siswa untuk menemukan makna pribadi dalam dunia sosial mereka dan membantu memecahkan dilema pribadi dalam bantuan kelompok. Dalam dimensi sosial model ini memudahkan individu untuk bekerjasama dalam mengaalisis kondisi sosial, khususnya masalah kemanusiaan.

Menurut Roemlah (dalam Darmawan, 2015) penjelasan mengenai macam-macam role-play sebagai berikut; (a) Sosiodrama adalah permainan peran yang ditujukan untuk memecahlan masalah sosial yang timbul dalam hubungan antar manusia; (b) Psikodrama merupakan permainan peran yang bertujuan agar individu yang bersangkutan dapat memperoleh pengertian yang lebih baik tentang dirinya, dapat menemukan konsep dirinya, menyatakan kebutuhankebutuhannya; (c) Bermain peran terstruktur adalah permainan peran dimana fasilitator menentukan struktur dan menjelaskan pada pertas permainan; (d)Bermain peran tidak terstruktur, adalah permainan peran dimana hubungan antara pemain utama dengan pemeran-pemeran lain dalam permainan tidak ditentukan oleh fasilitator tetapi oleh para anggota kelompok.

Bullying Menurut Afriana dkk, (2014) merupakan sebuah kata serapan dari bahasa Inggris. Bullying berasal dari kata bully yang artinya penggertak, atau orang yang mengganggu orang yang lemah. Pihak pelaku bullying biasa disebut bully. bullying merupakan sebuah situasi dimana terjadinya penyalahgunaan kekuatan/kekuasaan yang dilakukan oleh seorang/kelompok yang 
melakukan tindakan negatif karena merasa memiliki kekuasaan dan kekuatan dengan menyakiti orang lain secara mental atau fisik yang dilakukan tidak hanya sekali bahkan dapat berkelanjutan sehingga dapat merugikan orang lain dan mengakibatkan seseorang dalam keadaan tidak nyaman atau terluka.

Menurut Yayasan Semai Jiwa Insani (dalam Afriana, 2014) secara umum, bullying dapat dikelompokkan pada tiga kategori, yaitu: (1) Bullying fisik seperti memukul, mendorong, mencekik, menggigit, menampar, menendang, meninju dan lain-lain. (2) Bullying verbal seperti memberikan julukan nama, celaan, fitnah, dan lain-lain. (3) Bullying mental/psikologis seperti memandang dengan sinis, menjulurkan lidah, menampilkan ekspresi wajah yang merendahkan, dan lainlain.

Seseorang atau sekelompok orang yang menjadi pelaku bullying memiliki karakteristik tertentu. Karakteristik pelaku menurut Priyatna (dalam Darmawan, 2015) yaitu; (a) Mudah emosi, sering marah atau sensitif ketika terjadi sesuatu yang tidak sesuai dengan keinginannya dan biasanya sesuatu tersebut dilakukan oleh korban; (b) Mudah frustasi, pelaku bullying mudah menyerah sehingga sering tertekan dengan keadaan yang sedang dihadapi; (c) Kurang memiliki empati pada orang lain, pelaku tidak berfikir tentang perasaan atau keadaan korban yang dibullying dan hanya memikirkan kesenangannya sendiri membuat pelaku percaya diri tinggi untuk menindas korbannya; (d) Sulit mengikuti aturan, biasanya pelaku bullying adalah orang yang tidak pernah taat dengan peraturan yang ada, contohnya peraturan di sekolah seperti berkelahi, bolos sekolah, menjaili orang lain atau bahkan tawuran; (e) Memandang kekerasan sebagai sesuatu yang wajar, karena kebiasaan berperilaku bullying maka pelaku kurang memiliki rasa iba terhadap orang lain. Pelaku juga sering melihat dan melakukan bullying sehingga memandang bullying merupakan hal yang wajar bagi dia.

Hipotesis yang dirumuskan dalam penelitian ini adalah Hipotesis I berbunyi, Konseling kelompok pendekatan analisis transaksional teknik role playing berpengaruh terhadap penurunan perilaku bullying siswa kelas $\mathrm{X}$ di SMA Negeri Darussholah Singojuruh. Sedangkan Hipotesis II berbunyi, Terdapat perbedaan pengaruh terhadap penurunan perilaku bullying terhadap siswa kelas X di SMA Negeri Darussholah Singojuruh antara kelompok kontrol dan kelompok eksperimen.

\section{METODE PENELITIAN}

Pelaksanaan penelitian dilakukan di SMA Negeri Darussholah Singojuruh. Populasi dalam penelitian ini adalah siswa- 


\section{FKIP Universitas PGRI Banyuwangi Seminar Nasional}

Pendidikan Budaya dan Sejarah: "Dibalik Revitalisasi Budaya"

ISBN: 978-602-72362-7-1

siswi kelas X IPS. Sebanyak 3 kelas yang berpartisipasi dalam penelitian ini yaitu kelas X IPS 1, X IPS 3, dan X IPS 4. Jumlah sampel dalam penelitian ini sebanyak 15 siswa yang mengacu pada jumlah populasi yang memenuhi kriteria.

Metode pengumpulan data ini terdapat dua jenis metode pengumpulan data yaitu pengumpulan data utama dan metode pengumpulan data pelengkap, metode pengumpulan data utama berupa kuesioner yang akan disebar pada siswa sedangkan metode data pelengkap berupa obeservasi dan wawancara.

Metode penelitian yang pertama teknik analisis deskripif data instrumen perilaku bullying dianalisis secara deskriptif dan dinyatakan dengan jenjang kualifikasi. Jenjang kualifikasi dikategorikan berdasarkan skor rata-rata $(\bar{X})$, mean ideal (Mi), dan standar deviasi ideal (SDi). Setelah itu dilanjutkan dengan uji prasyarat yang terdiri dari uji normalitas dan uji homogenitas, dimana uji normalitas merupakan sebaran data dilakukan untuk meyakinkan bahwa data yang dihasilkan dalam penelitian benarbenar berditribusi normal, sehingga dapat dilakukan dan uji homogenits digunakan untuk mengetahui apakah kelompokkelompok sampel berasal dari populasi yang sama.

Bila uji prasyarat anarkis diatas telah dilakukan maka dapat dilnjutkn dengan hipotesis sebagai langkah lanjut dalam penelitian ini, dilakukan suatu prosedur analisis terhadap data-data yang diperoleh peneliti. Tujuan dari analisis data ini adalah mengungkapkan apa yang ingin diketahui dari penelitian ini. Dalam menganalisis data yang diperoleh selama melakukan penelitian, penulis menggunakan dua analisis statistik, antara lain (1) analisis statistik correlated data/paired sampel t-test dan (2) analisis statistik uncorrelated data/independent sampel t-test. Dasar pengambilan keputusannya adalah : (1)Jika thitung > t tabel, maka $\mathrm{H}_{0}$ ditolak; (2) Jika t hitung $<\mathrm{t}$ tabel, maka $\mathrm{H}_{0}$ diterima Berdasarkan nilai probabilitasnya : (1) Jika probabilitas > 0,05 maka $\mathrm{H}_{0}$ diterima Jika probabilitas $<0,05$ maka $\mathrm{H}_{0}$ ditolak.

\section{RANCANGAN PENELITIAN}

Penelitian ini merupakan quasi experimental (eksperimen semu), dengan menggunakan rancangan Non Equivalent Pretest-Posttest Control Group Design. Rancangan control group design dipilih dengan pertimbangan bahwa dalam eksperimen semu, tidak memungkinkan untuk merandom subjek dalam kelompok populasi secara utuh. Selanjutnya pretest dan posttest berarti memberikan tes kepada subjek sebelum dan setelah perlakuan diberikan pada masing-masing kelompok. Rancangan ini dipilih karena penelitian ini 
merupakan penelitian terapeutik untuk mengetahui efektivitas atau pengaruh perlakuan terhadap variable terikat. Artinya rancangan pretest dan posttest digunakan untuk mengetahui pengaruh konseling kelompok pendekatan analisis transaksional teknik role playing terhadap penurunan bullying siswa kelas X di SMA Negeri Darussholah Singojuruh.

\begin{tabular}{|c|ccc|}
\hline $\mathrm{E}$ & $\mathrm{O}_{1}$ & $\mathrm{X}$ & $\mathrm{O}_{2}$ \\
\hline $\mathrm{K}$ & $\mathrm{O}_{1}$ & - & $\mathrm{O}_{2}$ \\
\hline
\end{tabular}

(Sumber: Dantes, 2012:97)

Keterangan :

E : Eksperimen

K : Kelompok Kontrol

$\mathrm{X}$ : Konseling analisis transaksional teknik role playing

- $\quad$ : Konseling kelompok tanpa teknik khusus

$\mathrm{O}_{1}$ : Pengamatan awal, berupa pre-test sebelum diberikan perlakuan.

$\mathrm{O}_{2}$ : Pengamatan akhir, yaitu pemberian post-test setelah diberikan perlakuan.

\section{REFERENSI}

Adhiputra, A.A. Ngurah. 2014. Konseling Kelompok Perspektif Teori Dan Aplikasi. Yogyakarta: Media Akademi.

Afriana Dina, dkk. 2014. Upaya Mengurangi Perilaku Bullying Di Sekolah Dengan Menggunakan Layanan Konseling Kelompok.
Jurnal dipublikasikan pada situs file:///C:/Users/alex/Downloads/648 2-12482-1-PB\%20(2).pdf di akses pada 29 maret 2018 pukul 18.03 WIB.

Corey, Gerald (Terjemahan E. Koswara). 2010. Teori dan Praktek Konseling dan Psikoterapi. Bandung: PT. Refika Aditama.

Darmawan, HK. 2015. Mengurangi Perilaku Bullying Melalui Metode Role Playing Pada Siswa Kelas VIII D Di SMP N 1 Tempel. Skripsi, Universitas Negeri Yogyakarta (online). Skripsi di publikasikan pada situs http://eprints.uny.ac.id/21953/1/Hen dra\%20Krisnadi\%20Darmawan_091 04244017.pdf di akses rabu 20 maret 2018 pukul 08.30 WIB.

Dantes, Nyoman. 2012. Metode Penelitian. Yogyakarta: Penerbit Andi.

Hermasyah Ari. 2017. Pemberian Layanan Konseling Kelompok Dengan Teknik Role Playing Untuk Mengurangi Perilaku Bullying Pada Peserta Didik Kelas VII Di SMP Gajah Mada Bandar Lampung. Skripsi. Fakultas Tarbiyah dan Keguruan Institut Agama Islam Negeri Raden Intan Lampung (online). Skripsi di publikasikan pada situs http://repository.radenintan.ac.id/167/1/

Skripsi_Pdf_NEW.pdf di akses 29 maret 2018 pukul 19.22 WIB.

Sitompul, DN. 2015. Pengaruh Penerapan Layanan Bimbingan Kelompok Teknik Role Playing Terhadap Perilaku Solidaritas Siswa Dalam Menolong Teman Di SMA Negeri 1 Rantau Utara T.A 2014/201. Jurnal di publikasikan pada situs https://media.neliti.com/media/publicati ons/42696-ID-pengaruh penerapanlayanan-bimbingan-kelompok-teknikrole-playing-terhadap-peril.pdf di akses 30 Maret 2018 pukul 12.40 WIB. 